\title{
A Generalized Approach to the Steady-State Efficiency Analysis of Torque-Adding Transmissions Used in Renewable Energy Systems
}

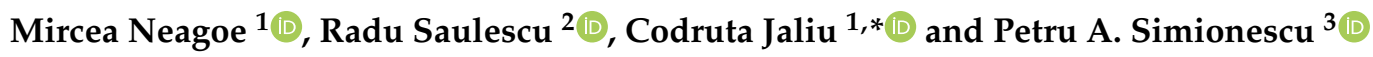 \\ 1 Renewable Energy Systems and Recycling R\&D Centre, Transilvania University of Brasov, \\ 500036 Brasov, Romania; mneagoe@unitbv.ro \\ 2 Design of Mechanical Elements and Systems R\&D Centre, Transilvania University of Brasov, \\ 500036 Brasov, Romania; rsaulescu@unitbv.ro \\ 3 Department of Engineering, College of Science and Engineering, Texas A \& M University Corpus Christi, \\ Corpus Christi, TX 78412, USA; pa.simionescu@tamucc.edu \\ * Correspondence: cjaliu@unitbv.ro; Tel.: +40-268-413-000
}

Received: 14 July 2020; Accepted: 31 August 2020; Published: 3 September 2020

\begin{abstract}
The paper presents a general approach to the steady-state efficiency analysis of one degree of freedom (1-DOF) speed increasers with one or two inputs, and one or two outputs, applicable to wind, hydro and marine-current power generating systems. The mechanical power flow, and the efficiency of this type of complex speed increasers, are important issues in the design and development of new power-generating systems. It is revealed that speed increases, with in-parallel transmission of the mechanical power from the wind or water rotors to the electric generator, have better efficiency than serial transmissions, but their efficiency calculus is still a challenging problem, solved in the paper by applying the decomposition method of complex speed increasers into simpler component planetary gear sets. Therefore, kinematic, steady-state torque and efficiency equations are derived for a generic 1-DOF speed increasers with two inputs and two outputs, obtained by connecting in parallel two gear mechanisms. These equations allow any speed increaser to be analysed with two inputs and one output, with one input and two outputs, and with one input and one output. We discuss a novel design of a patent-pending planetary-gear speed increaser, equipped with a two-way clutch, which can operate (in combination with the pitch adjustment of the rotors blades) in four distinct configurations. It was found that the mechanical efficiency of this speed increaser in the steady-state regime is influenced by the interior kinematic ratios, the input-torque ratio and by the meshing efficiency of its individual gear pairs. The efficiency of counter-rotating dual-rotor systems was found to be the highest, followed by systems with counter-rotating electric generator, and both have higher efficiency than conventional systems with one rotor and one electric generator with fixed-stator.
\end{abstract}

Keywords: wind energy; marine-current; hydro power; planetary gear; efficiency analysis

\section{Introduction}

Among the renewable energy technologies, hydro and wind energy conversion systems currently have the largest share of electrical power generation worldwide [1,2]. While, hydro-electric power is a more mature technology, improvements to wind, tidal-stream and marine-current energy conversion systems are reported every year $[3,4]$. The major research has looked at energy-conversion efficiency for the purpose of maximizing the use of the onsite renewable potential. Moreover, in the case of wind and hydro-power systems of medium and high capacity, power is transmitted from the wind or water turbine to the electric generator via a speed increaser, which amplifies the speed of the turbine shaft approximately three times in case of hydro-electric systems, and by around one hundred in 
case of wind power systems [5-7]. The best performing speed increasers in use, are one degree of freedom (1-DOF) or two degrees of freedom (2-DOF) planetary transmissions, which achieve higher efficiency, higher transmission ratios and smaller overall sizes than fixed-axis transmissions. However, these benefits come with added complexity, making the respective transmissions more difficult to design and optimize.

Many innovative solutions of wind and tidal turbines have been proposed in recent years (Figure 1), such as counter-rotating rotors [8-19], high-performance mechanical transmissions [3,20] and more compact and efficient electric generators, including the counter-rotating type [21,22]. Shin [8] proposed a large capacity wind turbine that uses multiple, smaller rotors in a spatial arrangement and a high-efficiency planetary speed increaser. Wacinski [11], Brander [12], Climescu et al. [13] and Oprina et al. [16] proposed different solutions of horizontal-axis wind turbines with two coaxial, counter-rotating rotors. Didane et al. [15,19] and West [18] evaluated the performance of new concepts of vertical-axis wind turbines with counter-rotating coaxial rotors. Designers of counter-rotating turbines (CRT) have resorted to a wide variety of innovative solutions of speed increasers, such as variable transmissions [23], differential transmissions with electric motor speed control [24], or novel planetary gears [25-28]. In spite of their larger size and lower efficiency, compared to their planetary counterparts, the most common solution of speed increasers implemented in wind, hydro and marine-current power generating systems, including of the CRT type, are fixed-axis gear mechanisms [29-31].

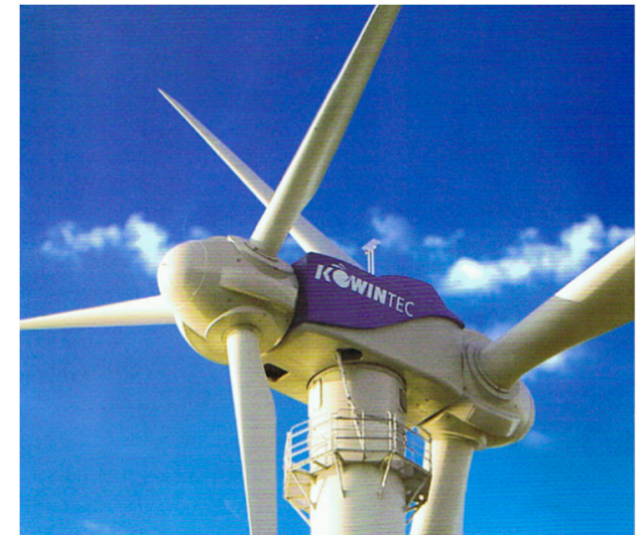

(a)

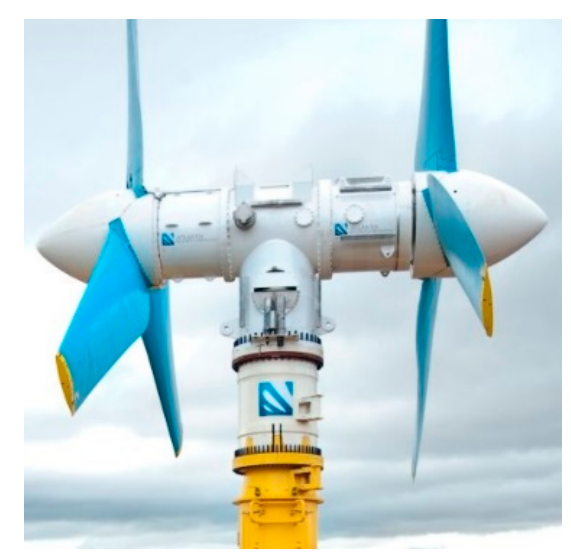

(b)

Figure 1. Dual rotor; (a) wind turbine of Kowintech Co. Ltd.; and (b) tidal turbine of SIMEC Atlantis Energy (formerly Atlantis Resources Corp.).

Planetary speed increasers are more appropriate for CRT applications because they ensure higher kinematic ratios and reduced overall size, at higher efficiency levels $[11,13,25,26,32-41]$. Furthermore, CRTs can employ 2-DOF transmissions to sum the input speeds [35,39] or 1-DOF planetary transmissions to sum the input torques of their two rotors $[40,41]$. The first type of speed increaser has been studied in conjunction with CRT and conventional generator [42-48], or with CRT and counter-rotating electric generator [41]. No generalization has been proposed. Rather, particular designs have been presented and analysed with respect to their performance. The 1-DOF planetary speed increasers with multiple inputs and outputs can operate both, with single or with counter-rotating wind or water rotors, and with conventional (fixed stator) or counter-rotating, (moving stator) electric generator [49-51]. Efficiency analysis of the mechanical transmissions used in wind, tidal-stream and marine-current energy conversion systems is an essential part of their design and development process $[52,53]$.

Based on the literature survey, the authors concluded that a comprehensive analysis of two-input, one degree of freedom planetary transmissions applicable to wind and water turbines is necessary, aiming to model the speed increaser efficiency in steady-state regime. 
The paper proposes a generic class of 1-DOF transmissions, with two inputs and two outputs, employing two planetary gear mechanisms connected in parallel. All four possible combinations, i.e., with one or two input rotors, and with one or two generator outputs can be obtained as particular cases. In Section 2, steady-state torque and efficiency equations are derived for this generic speed increaser class with two inputs and two outputs. Three other types of speed increasers, i.e., with two inputs and one output, with one input and two outputs, and with one input and one output are discussed in Section 3 as particular cases. A novel planetary speed increaser with cylindrical gears, which can operate in four variants by means of a two-way clutch [54], is analysed in Section 4 using bivariate three-dimensional (3D) plots. The paper ends with a summary of results and conclusions.

The main contributions of this paper involve the proposed 1-DOF speed increaser class that can operate in four functional cases. To the best of our knowledge, it is the first unifying modeling of transmission performance in different functional cases. The application example is done for a novel design of a patent-pending transmission [54]. The performance study of the transmission is outlined in this paper by using bivariate plots.

\section{Problem Formulation}

It is known that mechanical transmissions where power is transmitted in parallel, also known as split-power transmissions, have higher efficiency than transmissions formed with mechanisms connected in series [51]. The same applies to speed increasers used in wind, hydro and marine-current power generating systems that integrate two counter-rotating wind or water rotors and/or one counter-rotating electric generator. A 1-DOF transmission consisting of two 1-DOF mechanisms $M 1$ and $M 2$ is assumed, providing serial (Figure 2a) or in-parallel transmission (Figure $2 b, c)$ of the mechanical power from one rotor $(R)$ or from two counter-rotating rotors ( $R 1$ and $R 2)$ to a standard electric generator $(G)$ with a fixed stator, or to a generator with counter-rotating rotor $(G R)$ and moving stator (GS). Mechanisms $M 1$ and $M 2$ are characterized by their kinematic ratios $i_{1}$ and $i_{2}$, and efficiencies $\eta_{1}$ and $\eta_{2}$. Each shaft $x$ has an angular velocity $\omega_{x}$ and transmits a torque $T_{x}$ (where $x$ is either $R, R 1$, $R 2, G, G R$ or GS).

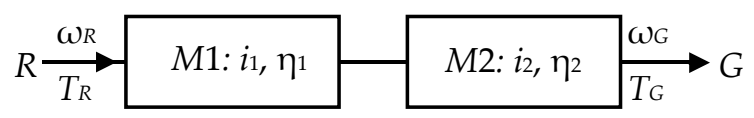

(a)

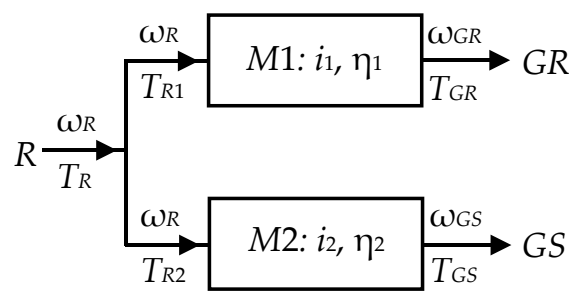

(b)

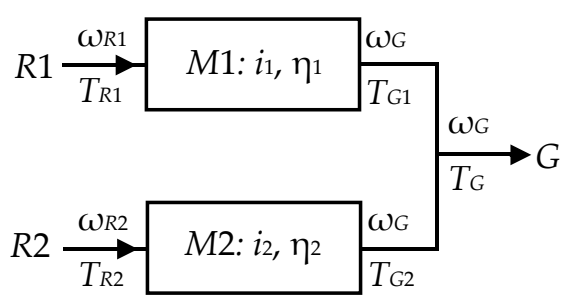

(c)

Figure 2. Block diagrams of 1-DOF speed increasers with two 1-DOF mechanisms $M 1$ and $M 2$, having: (a) one rotor and one standard electric generator; (b) one rotor and counter-rotating electric generator; (c) two counter-rotating input rotors with standard electric generator. $R, R 1$ and $R 2$ are wind or water rotors, $G$ and $G R$ are the electric-generator rotor; $G S$ is the electric generator stator; $T_{x}$ is the torque transmitted and $\omega_{x}$ is the angular velocity of shaft $x$; and $i_{1}$ and $i_{2}$ are the kinematic ratios and $\eta_{1}$ and $\eta_{2}$ are the efficiencies of constituent mechanisms $M 1$ and $M 2$.

As explained in references $[26,40,51]$, the efficiencies of the 1-DOF mechanical transmissions have been determined in closed-form, from kinematic, torque equilibrium and energy conservation considerations using Maple computer algebra system. 
The efficiencies of the 1-DOF mechanical transmissions in Figure 2 are calculated as follows.

- Case A (Figure 2a): speed increaser with one input $(R)$ and one output $(G)$ for which,

$$
\omega_{G}=\frac{\omega_{R}}{i_{1} i_{2}} ; T_{G}=-i_{1} i_{2} \eta_{1} \eta_{2} T_{R}
$$

the efficiency is:

$$
\eta_{A}=\frac{-P_{G}}{P_{R}}=\frac{-T_{G} \cdot \omega_{G}}{T_{R} \cdot \omega_{R}}=\eta_{1} \eta_{2}
$$

- Case B (Figure 2b): speed increaser with one input $(R)$ and two outputs (GR and $G S$ ) with:

$$
\begin{gathered}
\omega_{G R}=\frac{\omega_{R}}{i_{1}} ; \omega_{G S}=\frac{\omega_{R}}{i_{2}} ; \omega_{G}=\omega_{G R}-\omega_{G S}=\frac{i_{2}-i_{1}}{i_{1} i_{2}} \omega_{R} \\
T_{R 1}=-\frac{T_{G R}}{i_{1} \eta_{1}} ; T_{R 2}=-\frac{T_{G S}}{i_{2} \eta_{2}} ; T_{R}=T_{R 1}+T_{R 2}
\end{gathered}
$$

Knowing that the torques transmitted to the rotor and to the moving stator of the electric-generator are equal but of opposite signs $\left(T_{G S}=-T_{G R}\right)$, the torque $T_{G}=T_{G R}$ and mechanical power $T_{G} \omega_{G}$ delivered to the electric generator are:

$$
T_{G}=T_{R} \frac{i_{1} i_{2} \eta_{1} \eta_{2}}{i_{1} \eta_{1}-i_{2} \eta_{2}} \text { and } T_{G} \cdot \omega_{G}=\eta_{1} \eta_{2} \frac{i_{2}-i_{1}}{i_{1} \eta_{1}-i_{2} \eta_{2}} T_{R} \cdot \omega_{R}
$$

These equations allow the efficiency of the transmission to be calculated as:

$$
\eta_{B}=\frac{-P_{G}}{P_{R}}=\frac{-T_{G} \cdot \omega_{G}}{T_{R} \cdot \omega_{R}}=\eta_{1} \eta_{2} \frac{i_{1}-i_{2}}{i_{1} \eta_{1}-i_{2} \eta_{2}}
$$

- $\quad$ Case $\mathbf{C}$ (Figure 2c): speed increaser with two inputs ( $R 1$ and $R 2)$ and one output $(G)$.

$$
\begin{gathered}
\omega_{G}=\frac{\omega_{R 1}}{i_{1}}=\frac{\omega_{R 2}}{i_{2}} ; \omega_{R 2}=\frac{i_{2}}{i_{1}} \omega_{R 1} \\
T_{G 1}=-i_{1} \eta_{1} T_{R 1} ; T_{G 2}=-i_{2} \eta_{2} T_{R 2} ; T_{G}=T_{G 1}+T_{G 2} \\
T_{G} \cdot \omega_{G}=-\frac{i_{1} \eta_{1} T_{R 1}+i_{2} \eta_{2} T_{R 2}}{i_{1}} \omega_{R 1}
\end{gathered}
$$

from where the efficiency of the transmission is calculated as:

$$
\eta_{C}=\frac{-P_{G}}{P_{R}}=\frac{-T_{G} \cdot \omega_{G}}{T_{R 1} \cdot \omega_{R 1}+T_{R 2} \cdot \omega_{R 2}}=\frac{i_{1} \eta_{1}-i_{2} \eta_{2} k_{t}}{i_{1}-i_{2} k_{t}}
$$

where $k_{t}$ is the input torque ratio:

$$
k_{t}=-\frac{T_{R 2}}{T_{R 1}}
$$

Assuming for convenience that the two component mechanisms $M_{1}$ and $M_{2}$ have equal efficiencies $\left(\eta_{1}=\eta_{2}=\eta\right)$ Equations (2), (6) and (10) become:

$$
\eta_{A}=\eta^{2} ; \eta_{B}=\eta ; \eta_{C}=\eta
$$

Equation (12) suggests that if mechanisms $M_{1}$ and $M_{2}$ have comparable efficiencies, the use of counter-rotating wind or water rotors, or of counter-rotating generator, results in better efficiencies compared to serial arrangements i.e., $\eta_{B}>\eta_{A}$ and $\eta_{C}>\eta_{A}$. In the next section, a general model for the 
efficiency analysis of a class of 1-DOF planetary speed increasers with two inputs and two outputs, consisting of two in-parallel planetary gear sets will be presented.

\section{Generalized Speed and Steady-State Torque Equations for 1-DOF Speed Increasers with Two Inputs and Two Outputs}

Figure 3 shows a general case of a 1-DOF speed increaser with two inputs and two outputs, obtained by connecting in parallel two planetary gear sets $M 1$ and M2. The main input will be from the primary wind or water-turbine rotor $R 1$, while the main output will be the generator rotor $G R$. The two planetary gear sets are connected through two links, one to the frame (i.e., body 0), and the second to both the secondary input-rotor $R 2$ and to stator $G S$ of the electric generator. The other input is connected to the primary rotor $R 1$, while the electric generator rotor $(G R)$ is connected to the other output.

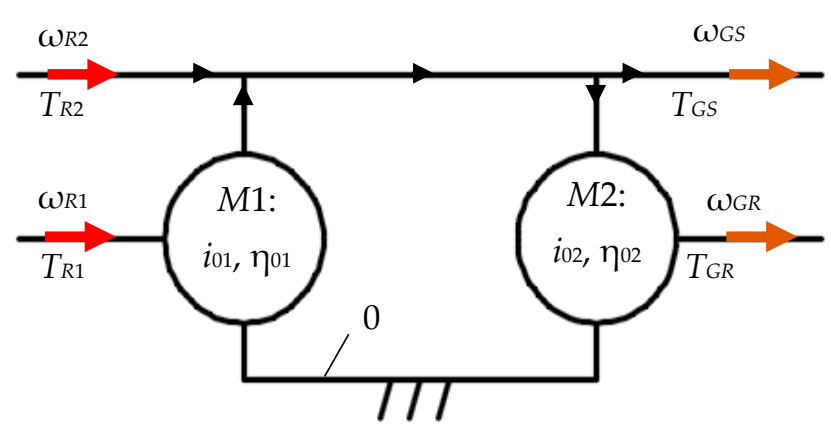

Figure 3. Block diagram of 1-DOF speed increasers with two counter-rotating inputs and two counter-rotating outputs, obtained by connecting in parallel the planetary gear sets M1 and M2.

With either the sun gear or planet carrier hold fixed to the frame, the two planetary gear sets $M 1$ and $M 2$ become 1-DOF mechanisms. Due to the constraints introduced by connecting the output of $M 1$ to the input of $M 2$, the speed increaser with two inputs and two outputs $(L=4)$ will have one degree of freedom.

Four functional variants of the 1-DOF speed increaser in Figure 3 are possible, depending on how the inputs and the outputs of the mechanism are activated:

(1) Variant V1: where both inputs $R 1$ and $R 2$, and both outputs $G R$ and $G S$ are active $(L=4)$. A system with two counter-rotating rotors and one counter-rotating electric generator is obtained.

(2) Variant V2: where both inputs $R 1$ and $R 2$ and the electric-generator output $G R$ are active $(L=3)$. In this case, a system with two counter-rotating rotors and a standard electric generator with $\omega_{G S}=0$ is obtained.

(3) Variant V3: where the main input $R 1$ and both outputs are active $(L=3)$, case in which a system with one rotor $\left(T_{R 1} \neq 0\right.$ and $\left.T_{R 2}=0\right)$ and one counter-rotating electric generator is obtained.

(4) Variant V4: where only the main input $R 1$ and the main output to the generator rotor $G R$ are active $(L=2)$. This results in a system with one rotor $\left(T_{R 1} \neq 0\right.$ and $\left.T_{R 2}=0\right)$ and a standard electric generator with $\omega_{G R} \neq 0$ and $\omega_{G S}=0$.

A 1-DOF mechanism with two inputs and two outputs $(L=4)$ is characterized by the following kinematic and static properties [51]:

(1) It has one independent external angular velocity, with $\omega_{R 1}$ assumed the independent kinematic parameter;

(2) It has three angular-velocity transmission functions, i.e., three of the external angular velocities depend on the independent velocity i.e., $\omega_{R 2}=\omega_{R 2}\left(\omega_{R 1}\right), \omega_{R G}=\omega_{R G}\left(\omega_{R 1}\right), \omega_{G S}=\omega_{G S}\left(\omega_{R 1}\right)$;

(3) It has one torque-transmission function $T_{R 1}=T_{R 1}\left(T_{R 2}, T_{G R}, T_{G S}\right)$ i.e., one dependent external torque (the primary rotor torque $T_{R 1}$ ) and three independent external torques i.e., $T_{R 2}, T_{G R}$ and $T_{G S}$. 
It is also known that these transmission functions are linear, except for non-circular gears. As a result, the transmission functions for angular velocities can be written as,

$$
\omega_{G R}=a \cdot \omega_{R 1} ; \omega_{R 2}=b \cdot \omega_{R 1} ; \omega_{G S}=c \cdot \omega_{R 1}
$$

where coefficients $a, b$ and $c$ are constant, and have meanings of kinematic ratios. The dependent torque $T_{R 1}$ can be written as,

$$
T_{R 1}=A \cdot T_{G R}+B \cdot T_{R 2}+C \cdot T_{G S}
$$

where coefficients $A, B$ and $C$ are also constant and have meanings of torque ratios.

The counter-rotating electric generator is characterized by the relative angular velocity $\omega_{G}$ between the rotor and the stator, and by the property that the rotor torque $T_{G R}$ and the stator torque $T_{G S}$ are equal and of opposite signs:

$$
\omega_{G}=\omega_{G R}-\omega_{G S}=(a-c) \omega_{R 1} ; T_{G S}=-T_{G R}
$$

The efficiency $\eta$ of a 1-DOF speed increaser with two inputs and two outputs is defined as the ratio between the sum of output powers over the sum of input powers. Since efficiency must be positively, and since the output powers of a mechanism are always negative, the efficiency equation writes,

$$
\eta=-\frac{\omega_{G R} T_{G R}+\omega_{G S} T_{G S}}{\omega_{R 1} T_{R 1}+\omega_{R 2} T_{R 2}}
$$

or by using coefficients $a, b, c, A, B$ and $C$ it becomes:

$$
\eta=-\frac{a-c}{A-C} \frac{T_{R 1}-B T_{R 2}}{T_{R 1}+b T_{R 2}}
$$

The input-torque ratio $k_{t}$ in Equation (11) varies from zero (i.e., $T_{R 2}=0$ ) to a maximum value, depending on the geometry of the two rotors $R 1$ and $R 2$, where the most common method of changing torque $T_{R 2}$ is to adjust the pitch angle of the rotor blades. The efficiency of the above four variants $\mathbf{V 1} \ldots \mathbf{V} 4$ can be obtained by considering particular forms of Equations (11) and (17) as follows:

For variant V1 with two inputs $(R 1, R 2)$ and two outputs $(G R, G S)$ :

$$
\eta_{V 1}=-\frac{(a-c)\left(1+k_{t} B\right)}{(A-C)\left(1-k_{t} b\right)}
$$

For variant V2 with two inputs $(R 1, R 2)$ and one output $(G R)$, i.e., $\omega_{G S}=0$ :

$$
\eta_{V 2}=-\frac{a\left(1+k_{t} B\right)}{A\left(1-k_{t} b\right)}
$$

For variant V3 with one input (R1), i.e., $k_{t}=0$, and two outputs $(G R, G S)$ :

$$
\eta_{V 3}=-\frac{a-c}{A-C}
$$

For variant V4 with one input (R1), i.e., $k_{t}=0$, and one output $(G R)$, i.e., $\omega_{G S}=0$ :

$$
\eta_{V 4}=-\frac{a}{A}
$$

Coefficients $a, b, c$ and $A, B, C$ in Equations (18)-(21) can be determined by applying the principle of superposition. An example on how these coefficients can be determined for the case of a planetary speed increaser with cylindrical gears will be presented next. 


\section{Case Study Analysis}

In this section, a novel cylindrical-gear planetary speed increaser will be considered. Its unique feature is that the input and output motions have opposite directions, provided by planet gear 2 in series with planet gear 3 (see Figure $4 a$ ).
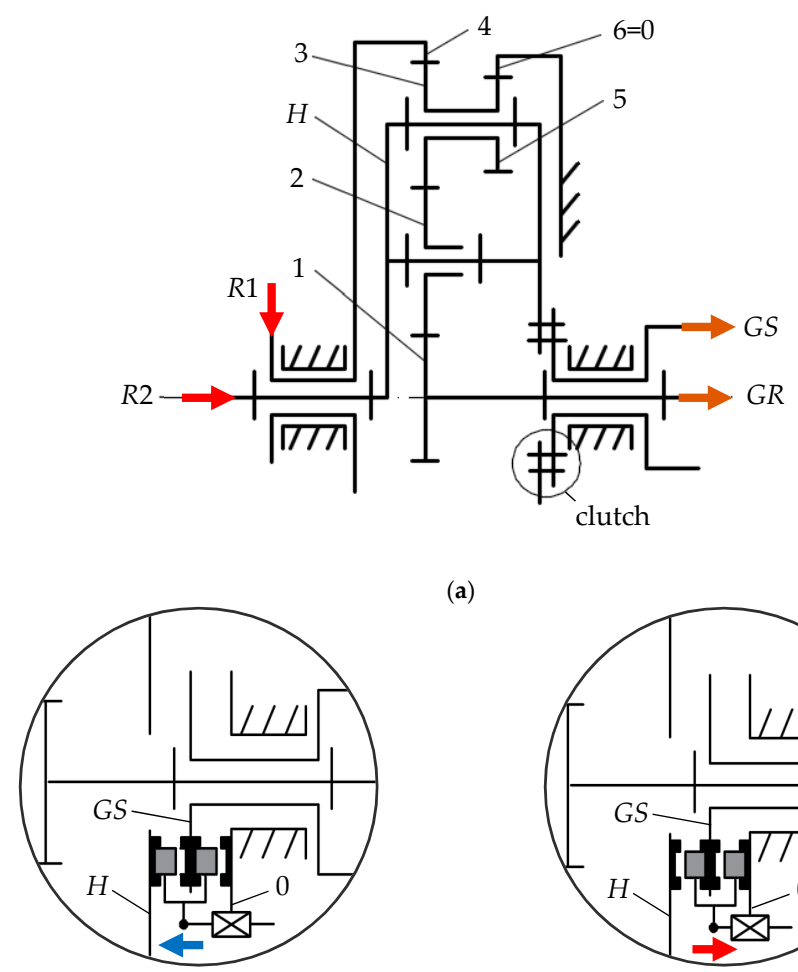

(a)

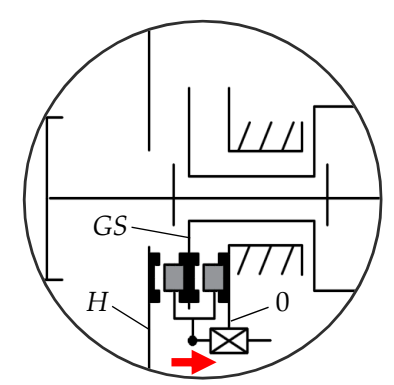

(b)

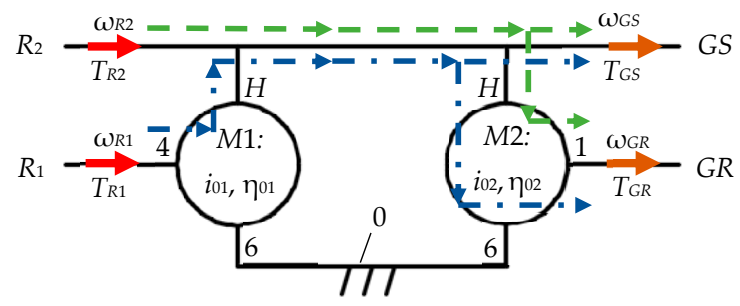

(c)

Figure 4. 1-DOF cylindrical-gear speed increaser in a generalized configuration with two inputs and two outputs: (a) structural diagram; (b) detail of the two-way clutch (left) in the $H \equiv G S$ position and (right) in the GS $\equiv 0$ position; (c) block diagram showing the input-output power flow.

Ring gear 4, connected to the primary rotor $R 1$ is the main input, and meshes with planet gear 3 , while the secondary input is the planet carrier $H$. Ring gear 6 which is fixed, meshes with gear 5 of the compound planet 3-5. Sun gear 1 is connected to the electric-generator rotor $(G R)$, while its stator is connected to carrier $H$ through a two-way clutch. This clutch allows the transmission of the mechanical power to output shafts GS and GR (see Figure 4b-left) or, by holding fixed the stator of the electric generator, to output $G R$ only (see Figure $4 \mathrm{~b}$-right).

According to the block diagram in Figure 4c, the speed increaser consists of planetary gear sets $M 1$ and $M 2$, of which $M 1$ (4-3-5-6-H) contains a compound planet with internal - internal gearing, and $M 2$ (1-2-3-5-6-H) has two planets in series with external-internal gearing. In this configuration, the two component mechanisms share the same moving carrier $H$ and the same fixed gear 6. 
In its general configuration with two inputs and two outputs, the four operating variants V1 to V4 become (see Figure 5):

(1) Variant V1: a system with two inputs and two outputs $(L=4)$, in which both input $R 1$ and $R 2$ and both output GR and GS are active. The input-output torque ratio $k_{t}>0$ is controlled by the blade-pitch angle of either or both rotors $R 1$ and $R 2$, while the clutch is set to connect carrier $H$ to GS (see Figure 4b-left);

(2) Variant V2: a system with two inputs and one output $(L=3)$, in which the output is connected to the electric-generator rotor GR, and stator GS is fixed by the clutch as shown in Figure 4b-right;

(3) Variant V3: a system with one input and two outputs $(L=3)$, obtained from V1 by deactivating the secondary rotor $R 2\left(k_{t}=0\right)$;

(4) Variant V4: a system with one input and one output $(L=2)$, obtained from variant V1 by deactivating the secondary rotor $R 2\left(k_{t}=0\right)$ and by connecting the electric-generator stator to the frame (see Figure $4 b$-right).
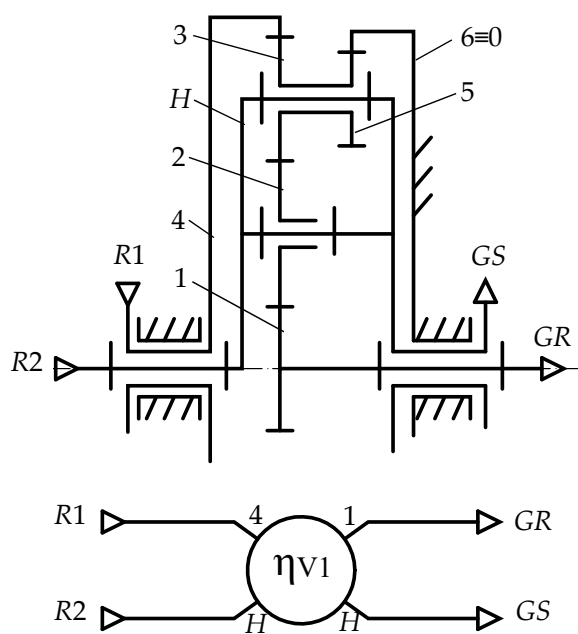

(a)
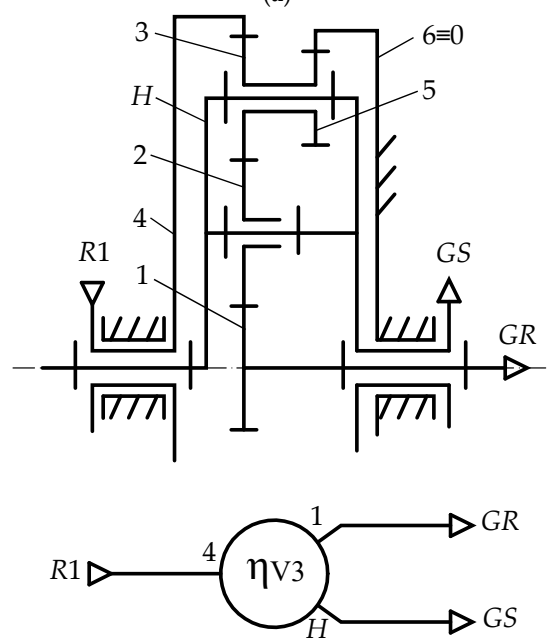

(c)
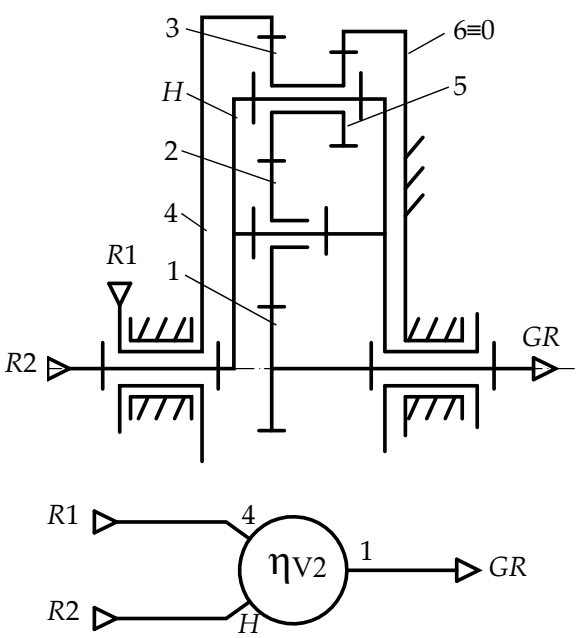

(b)

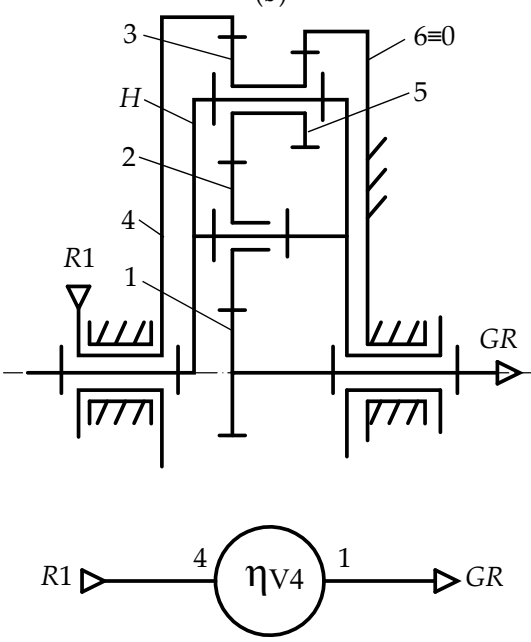

(d)

Figure 5. Structural and block diagrams of the 1-DOF speed increaser in Figure 4a with (a) two inputs and two outputs (variant V1); (b) two inputs and one output (variant V2); (c) one input and two outputs (variant V3) and (d) one input and one output (variant V4). 
The two component planetary gear sets $M 1$ and $M 2$ are characterized by the interior kinematic ratios $i_{01}$ and $i_{02}$,

$$
i_{01}=i_{46}^{H}=i_{43}^{H} \cdot i_{56}^{H}=\frac{z_{3} z_{6}}{z_{4} z_{5}}>0 ; i_{02}=i_{16}^{H}=i_{12}^{H} \cdot i_{23}^{H} \cdot i_{56}^{H}=\frac{z_{3} z_{6}}{z_{1} z_{5}}>0
$$

where $i_{x y}^{z}$ is the angular speed ratio of body $x$ and body $y$ relative to body $z$.

For obvious reasons, the number of teeth $z_{4}$ of ring gear 4 has to be bigger than the number of teeth $z_{1}$ of sun gear 1 (i.e., $z_{4}>z_{1}$ ), and according to Equation (22), inequality $i_{02}>i_{01}$ should also hold true.

Efficiencies $\eta_{01}$ and $\eta_{02}$ are the internal efficiencies of mechanisms $M 1$ and $M 2$ associated to the respective planetary gear sets, when carrier $H$ is fixed (see Equation (12), where $\eta_{0}$ is the efficiency of one gear pair, and efficiencies $\eta_{x y}^{z}$ correspond to the power being transmitted from member $x$ to member $y$ when $z$ is held fixed, and where $x, y$ can be either $1,2,3,4,5$ and $H$, while $z$ can be either 6 and $H$ ).

$$
\eta_{01}=\eta_{43}^{H} \cdot \eta_{56}^{H}=\left(\eta_{0}\right)^{2} ; \eta_{02}=\eta_{12}^{H} \cdot \eta_{23}^{H} \cdot \eta_{56}^{H}=\left(\eta_{0}\right)^{3}
$$

Coefficients $a, b, c$ defined in Equation (13) can be calculated by applying a motion-inversion relative to planet carrier $H$ [51]:

$$
a=i_{14}^{6}=\frac{\omega_{16}}{\omega_{46}}=\frac{1-i_{02}}{1-i_{01}} ; b=c=i_{H 4}^{6}=\frac{\omega_{H 6}}{\omega_{46}}=\frac{1}{1-i_{01}}
$$

In turn, torque-transmission functions are also linear equations according to Equation (25)

$$
T_{R 1}=T_{R 1}^{(G R)}+T_{R 1}^{(R 2)}+T_{R 1}^{(G S)} ; T_{R 1}^{(G R)}=A \cdot T_{G R} ; T_{R 1}^{(R 2)}=B \cdot T_{R 2} ; T_{R 1}^{(G S)}=C \cdot T_{G S}
$$

where $T_{R 1}^{(x)}$ is the torque at the primary rotor shaft $R 1$ obtained when all independent external torques are zero, except for $T_{x}$, and where coefficients $A, B, C$ defined in Equation (14) are determined by applying the principle of superposition.

For example, torque $T_{R 1}^{(G R)}$ is obtained for $T_{G R} \neq 0$ (mechanical power is transmitted only to electric-generator rotor $G R$ ) and for $T_{R 2}=T_{G S}=0$ (i.e., the secondary rotor $R 2$ and the stator of the electric generator are idling).

Considering only the power flow from $R 1$ to $G R$ yields,

$$
T_{R 1}^{(G R)} \cdot \omega_{46} \cdot \eta_{41}^{6}+T_{G R} \cdot \omega_{16}=0=>T_{R 1}^{(G R)}=-T_{G R} \cdot \frac{a}{\eta_{41}^{6}}
$$

where,

$$
\eta_{41}^{6}=\eta_{4 H}^{6} \cdot \eta_{H 1}^{6} ; \eta_{4 H}^{6}=\frac{1-\overline{i_{01}}}{1-i_{01}} ; \eta_{H 1}^{6}=\frac{1-i_{02}}{1-\overline{i_{02}}}
$$

and where $\overline{i_{01}}$ and $\overline{i_{02}}$ are torque ratios [51], defined as:

$$
\begin{aligned}
& \overline{i_{01}}=i_{01} \cdot \eta_{01}^{x_{1}} ; x_{1}=\operatorname{sign}\left(\frac{\omega_{4 H}}{\omega_{46}}\right)=\operatorname{sign}\left(\frac{i_{01}}{i_{01}-1}\right) \\
& \overline{i_{02}}=i_{02} \cdot \eta_{02}^{x_{2}} ; x_{2}=\operatorname{sign}\left(-\frac{\omega_{1 H}}{\omega_{16}}\right)=\operatorname{sign}\left(-\frac{i_{02}}{i_{02}-1}\right)
\end{aligned}
$$

In the above equations, sign represents the sign function, and $x_{1}=-1$ for $i_{01}<1$ and $x_{1}=+1$ for $i_{01}$ $>1, x_{2}=+1$ for $i_{02}<1$ and $x_{2}=-1$ for $i_{02}>1, i_{01} \neq 1, i_{02} \neq 1$. Because in a counter-rotating electric generator, the generator rotor must have a higher angular velocity than the stator i.e., $\left|\omega_{\mathrm{GR}}\right|>\left|\omega_{\mathrm{GS}}\right|$, then $|a|>|c|$, and as a result, $i_{02}>2$ and $x_{2}=-1$. 
From the condition that rotors $R 1$ and $R 2$ are counter-rotating, i.e., sign $\left(\omega_{R 1} \omega_{R 2}\right)=-1$, and since $b<0$, then $i_{01}>1$ and $x_{1}=+1$ (see Equations (13) and (24)). It also implies that:

$$
A=-\frac{a}{\eta_{41}^{6}}=-\frac{1-\overline{i_{02}}}{1-\overline{i_{01}}}=-\frac{1-i_{02} \cdot \eta_{02}^{-1}}{1-i_{01} \cdot \eta_{01}}
$$

Coefficients $B$ and $C$ are determined similarly to coefficient $A$, by considering the power flow from $R 1$ to $R 2$ and from $R 1$ to $R S$ :

$$
\begin{aligned}
& T_{R 1}^{(R 2)} \cdot \omega_{46} \cdot \eta_{4 H}^{6}+T_{R 2} \cdot \omega_{H 6}=0 \Rightarrow T_{R 1}^{(R 2)}=-T_{R 2} \cdot \frac{b}{\eta_{4 H}^{6}} \\
& T_{R 1}^{(R S)} \cdot \omega_{46} \cdot \eta_{4 H}^{6}+T_{R S} \cdot \omega_{H 6}=0 \Rightarrow T_{R 1}^{(R S)}=-T_{R S} \cdot \frac{c}{\eta_{4 H}^{6}}
\end{aligned}
$$

According to Equation (24), $b=c$ which yields:

$$
B=C=-\frac{b}{\eta_{4 H}^{6}}=-\frac{c}{\eta_{4 H}^{6}}=-\frac{1}{1-\overline{i_{01}}}=-\frac{1}{1-i_{01} \cdot \eta_{01}}
$$

By employing Equations (18)-(21), the efficiencies of the four variants of the 1-DOF planetary speed increaser are obtained.

For variant V1: two inputs and two outputs $(L=4)$ :

$$
\eta_{V 1}=\frac{i_{02}}{\overline{i_{02}}} \cdot \frac{1-\overline{i_{01}}-k_{t}}{1-i_{01}-k_{t}}=\eta_{02} \cdot \frac{1-i_{01} \eta_{01}-k_{t}}{1-i_{01}-k_{t}}
$$

For variant V2: two inputs and one output $\left(L=3, \omega_{G S}=0\right)$ :

$$
\eta_{V 2}=\frac{1-i_{02}}{1-i_{02} \eta_{02}^{-1}} \cdot \frac{1-i_{01} \eta_{01}-k_{t}}{1-i_{01}-k_{t}} .
$$

For variant V3: one input and two outputs $\left(L=3, k_{t}=0\right)$ :

$$
\eta_{V 3}=\eta_{02} \cdot \frac{1-i_{01} \eta_{01}}{1-i_{01}}
$$

For variant V4: one input and one output $\left(L=2, \omega_{G S}=0, k_{t}=0\right)$ :

$$
\eta_{V 4}=\frac{1-i_{02}}{1-i_{02} \eta_{02}^{-1}} \cdot \frac{1-i_{01} \eta_{01}}{1-i_{01}}
$$

\section{Numerical Simulations and Discussions}

Four independent parameters, i.e., $i_{01}, i_{02}, k_{t}$ and $\eta_{0}$ occur in the efficiency Equations (34)-(37) of the planetary speed increaser variants $\mathbf{V} \mathbf{1}, \mathbf{V} \mathbf{2}, \mathbf{V} \mathbf{3}$ and $\mathbf{V} 4$. The effects of these parameters upon overall efficiency and kinematic ratios of the respective speed increasers have been studied using bivariate plots as explained in $[55,56]$ (see Figures 6-10; note that in some of these plots the $z$-axis has been reversed for clarity). The value ranges of these four parameters have been considered as follows: the kinematic ratio of the speed increaser $i_{a G}=\omega_{G} / \omega_{R 1} \geq 3$, input torque ratio $k_{t}<2$ and efficiency of a typical pair of gears $\eta_{0}>0.94[57]$. 


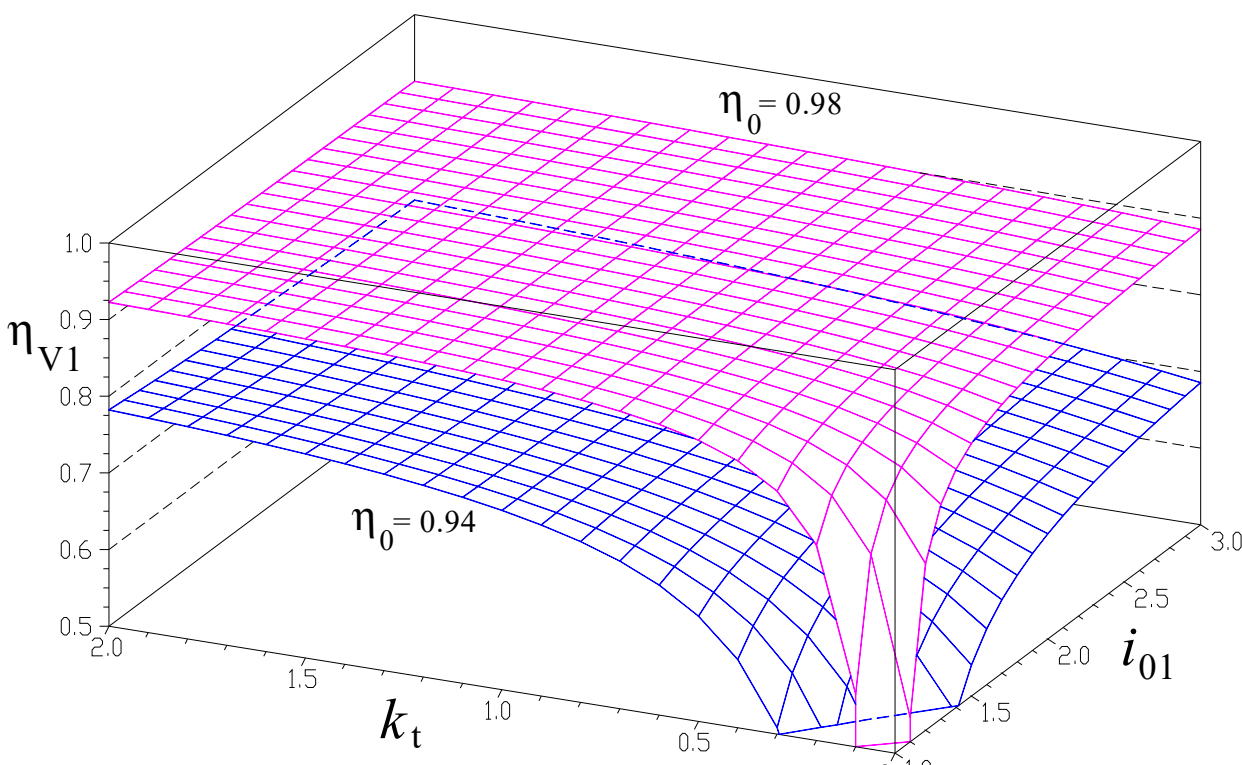

Figure 6. Efficiency of the 1-DOF speed increaser variant V1 (Figure 5a) as function of the interior kinematic ratio $i_{01}$, torque ratio $k_{t}$, and efficiency of each gear-pair $\eta_{0}=0.98$.

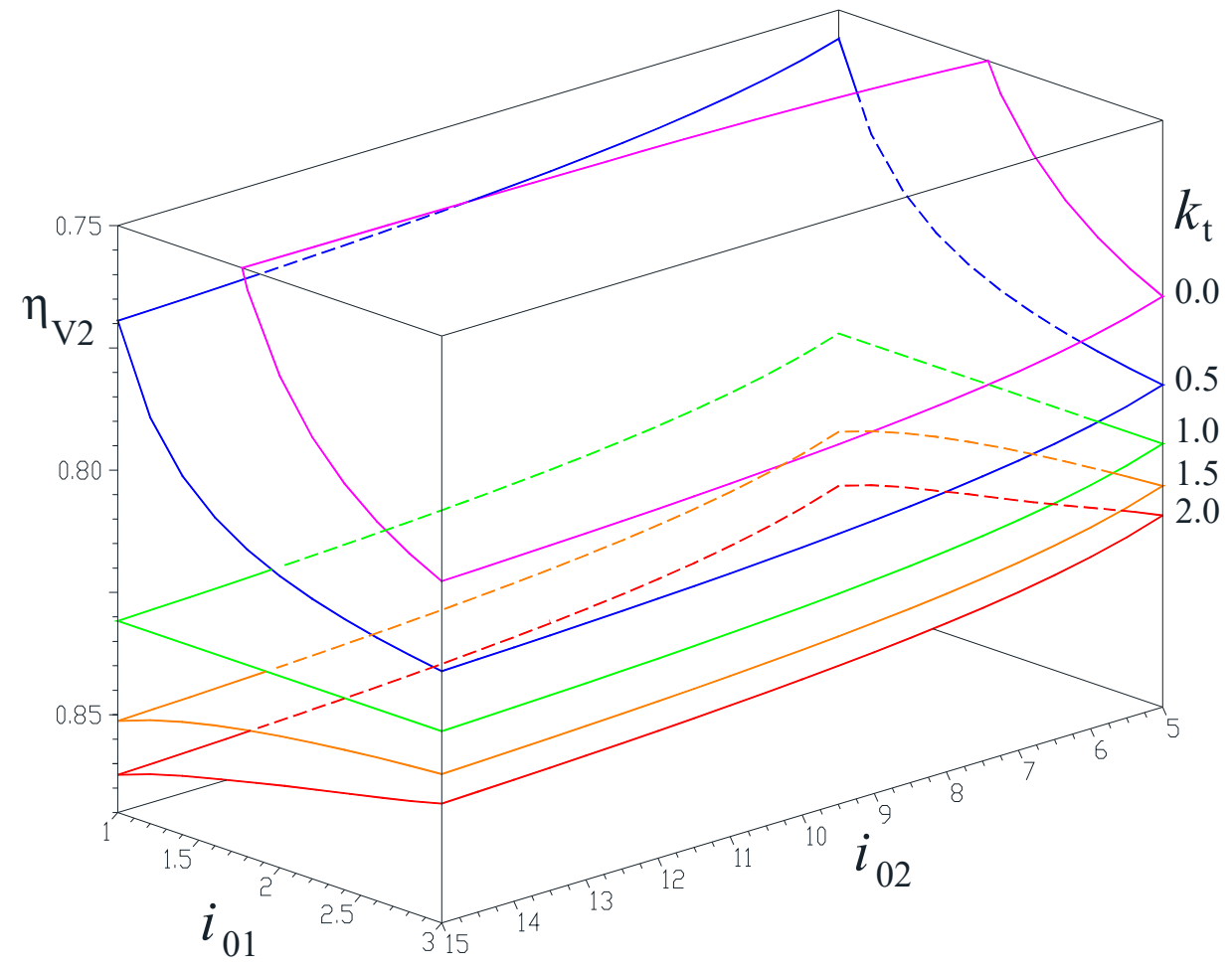

Figure 7. Efficiency of the 1-DOF speed increaser variant V2 (Figure 5b), as functions of the interior kinematic ratios $i_{01}$ and $i_{02}$, for torque ratios $k_{t}=0,0.5,1.0,1.5$ and 2.0, assuming $\eta_{0}=0.965$. 


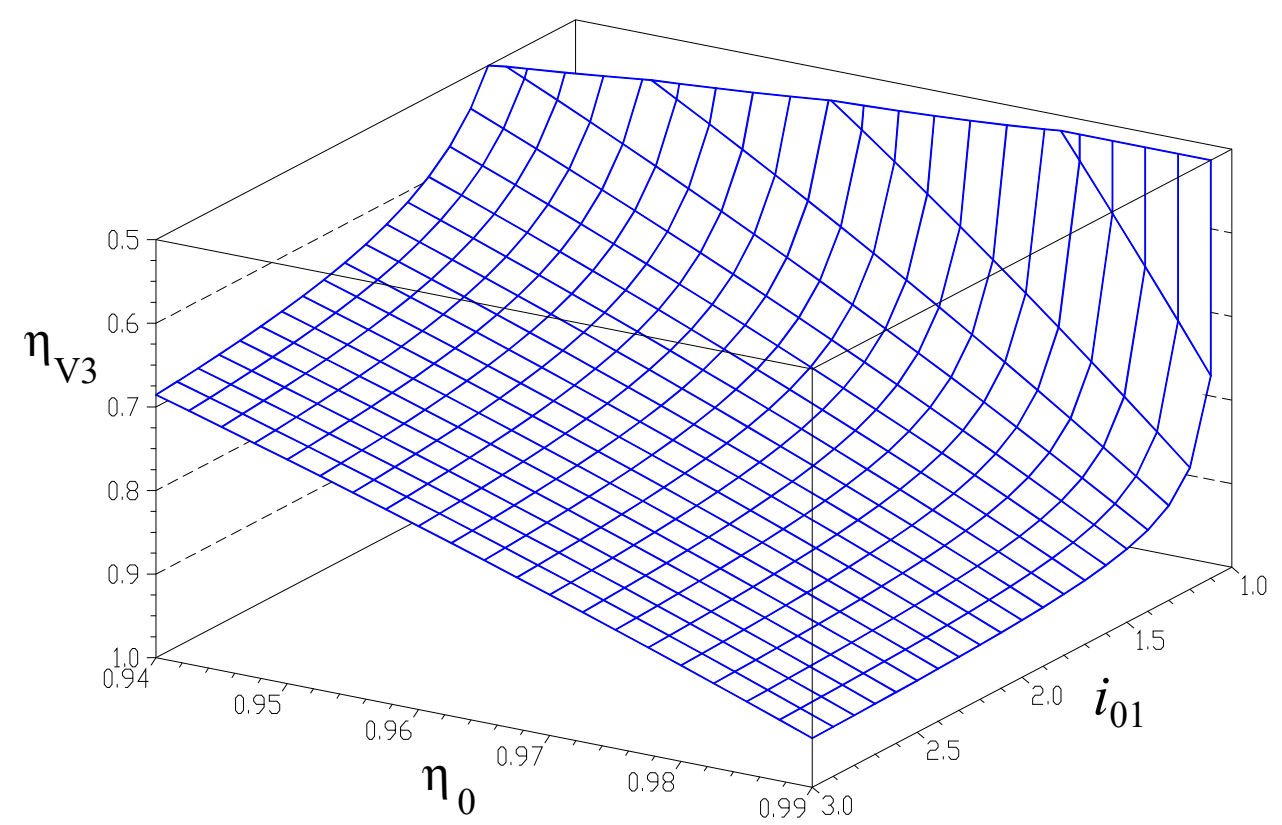

Figure 8. Efficiency of the 1-DOF speed increaser variant V3 (Figure 5c), as function of the interior kinematic ratio $i_{01}$ and $\eta_{0}$.

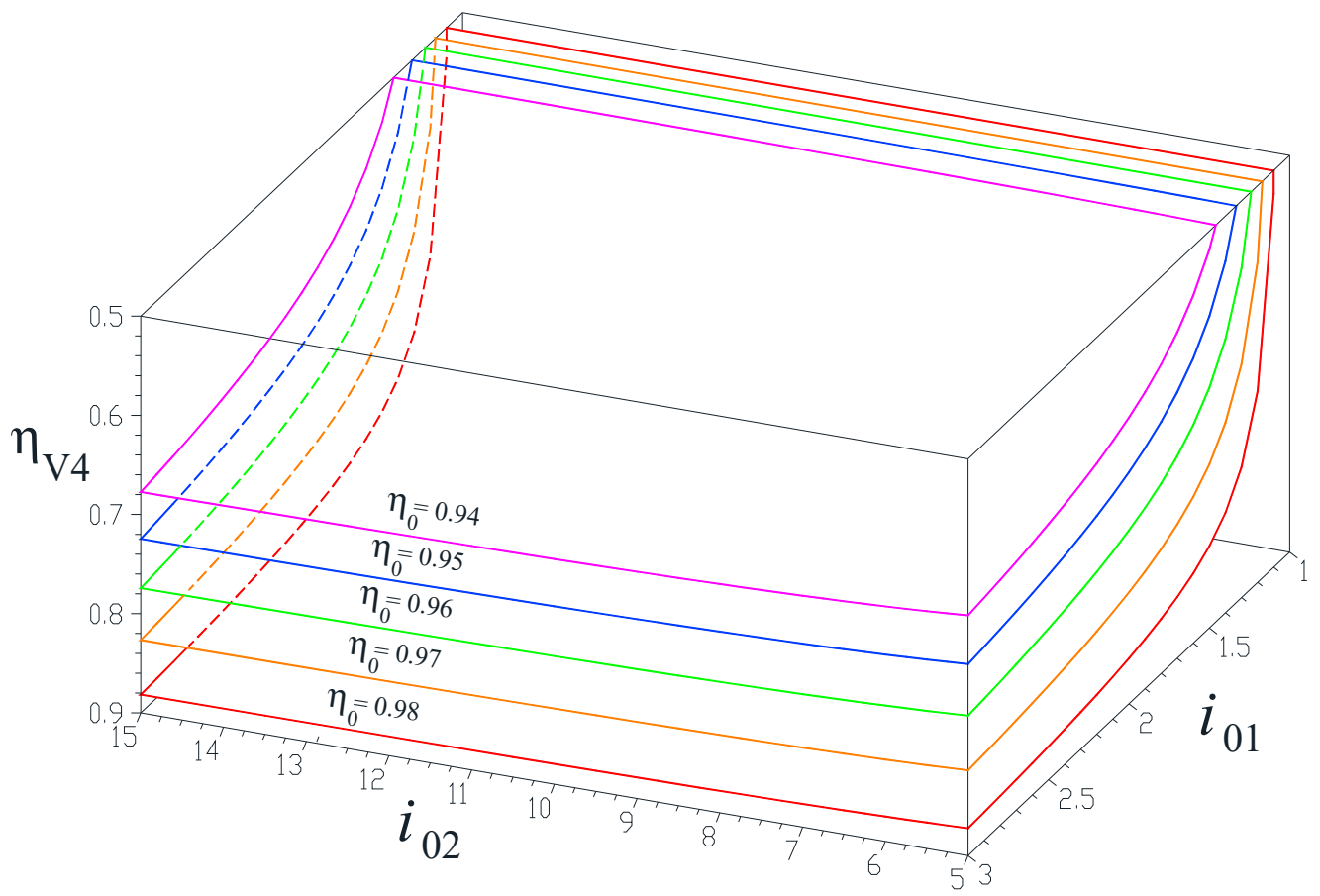

Figure 9. Efficiency of the 1-DOF speed increaser variant V4 (Figure $5 \mathrm{~d}$ ) as functions of the interior kinematic ratios $i_{01}$ and $i_{02}$, for various gear-pair efficiencies $\eta_{0}=0.94,0.95,0.96,0.97$ and 0.98 . 


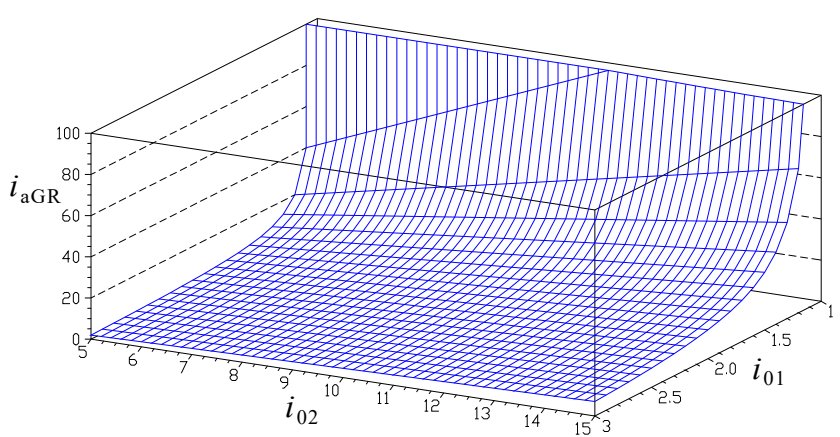

(a)

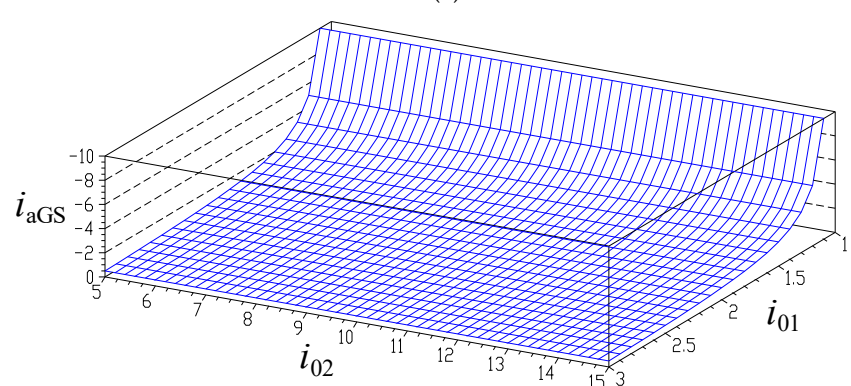

(b)

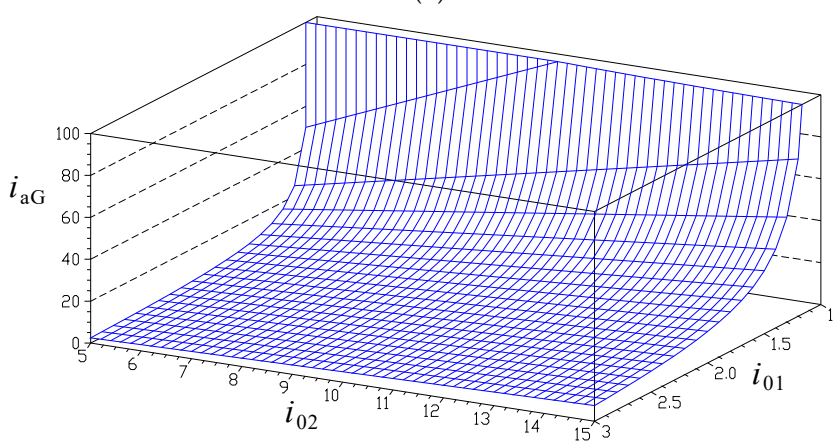

(c)

Figure 10. Variations of kinematic ratios (a) $i_{a \mathrm{GR}}$ (from R1 to GR), (b) $i_{a \mathrm{GS}}$ (from R1 to GS) and (c) $i_{a \mathrm{G}}$ (from $\mathrm{R} 1$ to $\mathrm{G}$ in of counter-rotating electric generator) as functions of the interior kinematic ratios $i_{01}$ and $i_{02}$.

According to Equation (34), the efficiency of a speed increasers with two counter-rotating wind or water rotors and counter-rotating electric generator (variant V1) depends on $i_{01}, k_{t}$ and $\eta_{0}$, and it is not influenced by the interior kinematic ratio $i_{02}$. As the plot in Figure 6 shows, the efficiency $\eta_{\mathrm{V} 1}$ of the speed increaser is influenced the most by the efficiency $\eta_{0}$ of its constituent gear pairs, resulting in more than $12 \%$ increase, for only $4 \%$ improvement in $\eta_{0}$ i.e., from $94 \%$ to $98 \%$. Consequently, care should be given to the manufacturing quality of the individual gears. Also, what is visible in Figure 7 is a rapid decrease of $\eta_{V 1}$ with a reduction of parameters $i_{01}$ and $k_{t}$, most noticeable for $i_{01}<1.75$ and $k_{t}<0.75$. From Figure 10c it additionally becomes apparent that for $1<i_{01}<2$, high values of the amplification ratio $i_{a G}$ are obtained. During the operation of a power generating system equipped with such a transmission, torque ratio $k_{t}$ will be adjusted via the pitch angles of the wind or water rotors. In the design stage, the anticipated range of $k_{t}$ should be correlated with interior ratio $i_{01}$ and gear-pair efficiency $\eta_{0}$ to achieve best speed increaser efficiency and a high amplification ratio $i_{a G}$.

In case of variant $\mathbf{V} \mathbf{2}$ of gear increasers (which is the same as variant V1 but with a locked stator, i.e., $\omega_{G S}=0$ ) Equation (35) indicates that the efficiency $\eta_{\mathrm{V} 2}$ of the increaser depends on all four parameters $i_{01}, i_{02}, k_{t}$ and $\eta_{0}$. Assuming that each gear-pair of the transmission has the same efficiency $\eta_{0}$ and equal to 0.965 , according to the plot in Figure $7, \eta_{\mathrm{V} 2}$ is influenced manly by the interior kinematic ratio $i_{01}$ and by the torque ratio $k_{t}$, and less by the interior ratio $i_{02}$. As $i_{02}$ increases and for $i_{01}$ and $k_{t}$ 
assumed constant, a slight increase of $\eta_{\mathrm{V} 2}$ is observed. Likewise, efficiency $\eta_{V 2}$ increases for $k_{t}<1$, and decreases slightly for $k_{t}>1$ as $i_{01}$ increases. For $k_{\mathrm{t}}=1$, efficiency $\eta_{\mathrm{V} 2}$ no longer depends on $i_{01}$, which may be interesting when large kinematic amplification ratios $i_{a G}$ are desired. Same as for variant $\mathbf{V 1}$, an increase of the torque ratio $k_{t}$ is accompanied by an increase in efficiency $\eta_{\mathrm{V} 2}$. The increase of $\eta_{\mathrm{V} 2}$ with $k_{t}$ is more significant for small values of $i_{01}$ than is for larger values of $i_{01}$.

The efficiency of gear transmission variant $\mathbf{V} 3$ with one input $R 1$ and two counter-rotating outputs GR and GS, depends only on $i_{01}$ and $\eta_{0}$ (see Equation (36)). The internal gear ratio $i_{01}$ does not affect the efficiency $\eta_{\mathrm{V} 3}$ of the increaser and $k_{t}=0$. The 3D plot in Figure 8 shows, for $i_{01}$ held constant, a linear correlation of efficiency $\eta_{\mathrm{V} 3}$ with $\eta_{0}$. Also apparent is a rapid drop of efficiency $\eta_{\mathrm{V} 3}$ with $i_{01}$, particularly for $i_{01}<1.75$.

Variant V4 of gear increaser is characterized by $k_{t}=0$ (there is only one input i.e., $R 1$ ) and by $\omega_{G S}=0$ (the generator has a fixed stator). According to Equation (37) its efficiency $\eta_{\mathrm{V} 4}$ depends on parameters $i_{01}, i_{02}$ and $\eta_{0}$. Higher values of the efficiency $\eta_{\mathrm{V} 4}$ are obtained for larger values of these three parameters, of which $\eta_{0}$ has the most effect, Figure 9 . Internal kinematic ratio $i_{02}$ has a smaller effect, however, a rapid drop in $\eta_{\mathrm{V} 4}$ is observed for $i_{01}$ approaching 1 .

Based on the same plots in Figures 6-9, the following additional conclusions can be drawn:

- Efficiencies $\eta_{\mathrm{V} 1}$ and $\eta_{\mathrm{V} 2}$ increase as the input torque ratio $k_{t}$ increases. This is explicable by the relative increase of the power from the secondary wind or water rotor $R 2$. It is worth mentioning that the power flow from R1 passes entirely through mechanism M1 and then through part of mechanism M2, while the power flow generated by R2 passes only partially through M2 and the rest is transmitted directly to the generator stator GS;

- The interior kinematic ratio $i_{01}$ influences strongly the speed-increaser efficiency in all four variants as $k_{t}$ approaching 0 , particularly if $1<i_{01}<1.75$. Furthermore, the mechanism locks (i.e., efficiency becomes negative) for $i_{01}$ approaching 1 ;

- The interior kinematic ratio $i_{02}$ does not occur in the efficiency Equations (34) and (36) for the speed increaser variants V1 and V3 with counter-rotating electric generator. Instead, efficiencies $\eta_{V 2}$ and $\eta_{V 4}$ (the cases with electric generator with a fixed stator) have markedly lower values for small values of parameter $i_{02}$, but increase with the increase of $i_{02}$;

- The quality of the component gears and therefore the individual gear pair efficiencies $\eta_{0}$, have a major influence upon the efficiency of the speed increaser, regardless of variant V1 to V4. Therefore, it is recommended that good quality gear pairs are used, in order to minimize losses and maximize the efficiency in transmitting mechanical power from wind or water rotors to the electric generator.

As a general conclusion, Figures 6-9 confirm that split-power transmissions have higher efficiencies than serial transmission. Overall, the best efficiencies are provided by variant V1, which combines the split input power (Figure 2c) with the split output power (Figure 2b). The second most efficient is variant V2 with two inputs and one output (Figure 2c), followed by variant V3 with a single rotor and counter-rotating electric generator (Figure $2 b$ ). The least performing variant is $\mathbf{V} \mathbf{4}$ with serial transmission of mechanical power (Figure 2a). Thus, the efficiency of hydro/tidal/wind systems can be increased by adopting either a split-input power transmissions, a split-output power transmissions, or a transmissions with power split both at input and at output.

The interior kinematic ratios $i_{01}$ and $i_{02}$ of the component mechanisms $M 1$ and $M 2$, directly influence the transmission of input angular speed $\omega_{\mathrm{R} 1}$ to the electric generator, and implicitly, the relative speed $\omega_{\mathrm{G}}$ between the generator rotor and stator. The plots in Figure 10, depicted for variant V1 with two inputs and two outputs, indicate that the amplification ratio $i_{a G}=\omega_{\mathrm{G}} / \omega_{\mathrm{R} 1}$ increases with the decrease of $i_{01}$ and with the increase of $i_{02}$. High kinematic ratios $i_{a G}$ can be obtained at reduced internal ratios $i_{01}$ (e.g., $i_{a G}=50$ for $i_{01}=1.2$ and $i_{02}=10$ ) and/or in combination with high values of internal ratio $i_{02}$ (e.g., $i_{a \mathrm{G}}=30$ for $i_{01}=1.5$ and $i_{02}=15$ ). 


\section{Conclusions}

This paper presented a generalized model of efficiency calculation of 1-DOF speed increasers applicable to hydro and wind energy conversion systems with two gear mechanisms in parallel. Possible operating modes involve one input or two counter-rotating inputs, and with a single or two generator outputs. The inputs are provided by two counter-rotating wind or water rotors, while the outputs are linked to the counter-rotating rotor and the stator of an electric generator.

It was found that the in-parallel or split-power transmissions have higher efficiency compared to the serial transmissions. The in-parallel power transmission can be achieved, either by using two counter-rotating wind or water rotors, or by employing an electric generator with counter-rotating rotor and stator. As a result, counter-rotating systems have higher efficiencies than conventional single input, single output systems.

For the general case of a speed increaser with two inputs and two outputs, an efficiency analysis has been performed where transmissions with only two inputs and one output; one input and two outputs, and with one input and one output result as particular cases. This approach has then been applied to a novel planetary gear speed increaser, which can operate in all four possible combinations using a built-in two-way clutch, and by adjusting the pitch angle of the wind or water rotors.

The results reveal that the speed-increasers with two inputs and two outputs have higher efficiency. The results presented in this paper offer design engineers a useful approach for the analysis and synthesis of high-performance wind/tidal/hydro electrical systems.

Author Contributions: Conceptualization, M.N., R.S. and C.J.; methodology, M.N., R.S., C.J., and P.A.S.; software, M.N., R.S. and P.A.S.; validation, M.N., R.S., C.J. and P.A.S.; formal analysis, M.N., R.S., and P.A.S.; investigation, M.N., R.S., C.J., P.A.S.; resources, M.N., R.S., C.J., and P.A.S.; data curation, M.N., R.S., C.J., and P.A.S.; writing — original draft preparation, M.N., R.S. and C.J.; writing—review and editing, M.N. and P.A.S.; visualization, M.N., R.S., C.J., and P.A.S.; supervision, M.N. All authors contributed equally to editing and revising of this review. All authors have read and agreed to the published version of the manuscript.

Funding: This research received no external funding.

Acknowledgments: The comments, suggestions and recommendations for future research by the anonymous reviewers are gratefully acknowledged.

Conflicts of Interest: The authors declare no conflict of interest.

\section{Nomenclature}

$\begin{array}{ll}\text { CRWT } & \text { Counter-Rotating Wind Turbine } \\ S I & \text { Speed increaser } \\ R & \text { Rotor } \\ R 1 & \text { Primary rotor } \\ R 2 & \text { Secondary rotor } \\ P & \text { Power } \\ \omega & \text { Angular speed } \\ T & \text { Torque } \\ k_{t} & \text { Ratio of the input torques } \\ z & \text { Gear teeth number } \\ H & \text { Satellite carrier } \\ a, b, c & \text { Kinematic coefficients } \\ A, B, C & \text { Static coefficients } \\ D O F & \text { Degree of Freedom } \\ M 1, M 2 & \text { Mechanism } 1 \text { or } 2 \\ L & \text { Total number of inputs and outputs } \\ G & \text { Standard electric generator } \\ G R & \text { Electric generator rotor } \\ G S & \text { Electric generator stator } \\ i & \text { Kinematic ratio } \\ i_{01,2} & \text { Interior kinematic ratio of the mechanism } \\ i_{a} & \text { M1,2 } \\ \eta & \text { Amplification kinematic ratio } \\ \eta_{01,2} & \text { Efficiency of the speed increaser } \\ \eta_{0} & \text { Interior efficiency of the mechanism M1,2 } \\ & \text { Efficiency of a gear pair } \\ \end{array}$




\section{References}

1. Dincer, I. (Ed.) Comprehensive Energy Systems; Elsevier Science \& Technology: Amsterdam, The Netherlands, 2018; ISBN 978-0-12-809597-3.

2. World Energy Resources Charting the Upsurge in Hydropower Development. 2015. Available online: www.worldenergy.org/publications/entry/charting-the-upsurge-in-hydropower-development-2015 (accessed on 19 August 2020).

3. Jaliu, C.; Diaconescu, D.V.; Neagoe, M.; Saulescu, R. The eco-impact of small hydro implementation. Environ. Eng. Manag. J. 2009, 8, 837-841. [CrossRef]

4. Hydro Power. Available online: https://ec.europa.eu/research/energy/index.cfm?pg=area\&areaname= renewable_hydro (accessed on 19 August 2020).

5. Visa, I.; Jaliu, C.; Duta, A.; Neagoe, M.; Comsit, M.; Moldovan, M.; Ciobanu, D.; Burduhos, B.; Saulescu, R. The Role of Mechanisms in Sustainable Energy Systems; Transilvania University Press: Brasov, Romania, 2015; ISBN 978-606-19-0571-3.

6. Manwell, J.F.; McGowan, J.G.; Rogers, A.L. Wind Energy Explained: Theory, Design and Application; Wiley: Hoboken, NJ, USA, 2009.

7. Pelikan, B.; Armand, F.; Schleiss, A.; Bollaert, B.; Manso, P.; Bard, J.; O’Nians, J.; Denis, V.; Corbet, J.-P.; Soderberg, C.; et al. Guide on How to Develop a Small Hydropower Plant; European Small Hidro-Power Association (ESHA): Brussels, Belgium, 2004.

8. Shin, C. Multi-Unit Rotor Blade System Integrated Wind Turbine. U.S. Patent No. 5876181, 2 March 1999.

9. Appa, K. Energy Innovations Small Grant (EISG) Program (Counter Rotating Wind Turbine System); EISG Final Report; EISG: Shores, CA, USA, 2002; Available online: https://www.eai.in/ref/invent/upload/00-09\% 2520FAR\%2520Appendix\%2520A.pdf (accessed on 19 August 2020).

10. Jung, S.; No, T.; Ryu, K. Aerodynamic performance prediction of a $30 \mathrm{~kW}$ counter-rotating wind turbine system. Renew. Energy 2005, 30, 631-644. [CrossRef]

11. Wacinski, A. Drive Device for a Windmill Provided with Two Counter-Rotative Propellers. U.S. Patent 7,384,239, 10 June 2008.

12. Brander, M. Bi-Directional Wind Turbine. U.S. Patent Application 2008/0197639 A1, 21 August 2008.

13. Climescu, O.; Saulescu, R.; Jaliu, C. Specific features of a counter-rotating transmission for renewable energy systems. Environ. Eng. Manag. J. 2011, 10, 1105-1113. [CrossRef]

14. Hwang, B.; Lee, S.; Lee, S. Optimization of a counter-rotating wind turbine using the blade element and momentum theory. J. Renew. Sustain. Energy 2013, 5, 052013. [CrossRef]

15. Didane, D.H.; Rosly, N.; Zulkafli, M.F.; Shamsudin, S.S. Performance evaluation of a novel vertical axis wind turbine with coaxial contra-rotating concept. Renew. Energy 2015, 115, 353-361. [CrossRef]

16. Oprina, G.; Chihaia, R.A.; El-Leathey, L.A.; Nicolaie, S.; Babutanu, C.A.; Voina, A. A review on counter-rotating wind turbines development. J. Sustain. Energy 2016, 7, 91-98.

17. Vasel-Be-Hagh, A.; Archer, C. Wind farms with counter-rotating wind turbines. Sustain. Energy Technol. Assess. 2017, 24, 19-30. [CrossRef]

18. West, R. Wind Turbine System. U.S. Patent 10,316,820B2, 11 June 2019.

19. Didane, D.H.; Rosly, N.; Zulkafli, M.F.; Shamsudin, S.S. Numerical investigation of a novel contra-rotating vertical axis wind turbine. Sustain. Energy Technol. Assess. 2019, 31, 43-53. [CrossRef]

20. Jaliu, C.; Saulescu, R.; Diaconescu, D.V.; Neagoe, M. Conceptual design of a chain speed increaser for small hydropower stations. In Proceedings of the ASME 2009 International Design Engineering Technical Conferences \& Computers and Information in Engineering Conference IDETC/CIE 2009, San Diego, CA, USA, 30 August-2 September 2009; ISBN 978-0-7918-3856-3.

21. Booker, J.D.; Mellor, P.H.; Wrobel, R.; Drury, D. A compact, high efficiency contra-rotating generator suitable for wind turbines in the urban environment. Renew. Energy 2010, 35, 2027-2033. [CrossRef]

22. Erturk, E.; Sivrioglu, S.; Bolat, F.C. Analysis Model of a Small Scale Counter-Rotating Dual Rotor Wind Turbine with Double Rotational Generator Armature. Int. J. Renew. Energy Res. 2018, 8, 1849-1858.

23. Hall, J.F.; Mecklenborg, C.A.; Chen, D.; Pratap, S.B. Wind energy conversion with a variable-ratio gearbox: Design and analysis. Renew. Energy 2011, 36, 1075-1080. [CrossRef]

24. Jelaska, D.; Podrug, S.; Perkusic, M. A novel hybrid transmission for variable speed wind turbines. Renew. Energy 2015, 83, 78-84. [CrossRef] 
25. Saulescu, R.; Neagoe, M.; Munteanu, O.; Cretescu, N. Performance Analysis of a Novel Planetary Speed Increaser Used in Single-Rotor Wind Turbines with Counter-Rotating Electric Generator; Materials Science and Engineering-IOP Conference Series: Materials Science and Engineering; IOP Publishing Ltd.: Bristol, UK, 2016. [CrossRef]

26. Neagoe, M.; Saulescu, R.; Jaliu, C.; Cretescu, N. Novel Speed increaser used in counter-rotating wind turbines. In New Advances in Mechanisms, Mechanical Transmissions and Robotics, Mechanisms and Machine Science 46; Springer: Berlin, Germany, 2017; pp. 143-151. [CrossRef]

27. Jaliu, C.; Diaconescu, D.V.; Neagoe, M.; Saulescu, R. Dynamic features of speed increasers from mechatronic wind and hydro systems. Part I. Structure Kinematics. In Proceedings of the Second European Conference on Mechanism Science EUCOMES 08, Casino, Italy, 17-20 September 2008; Springer: Dordrecht, The Netherlands, 2008; pp. 355-363, ISBN 987-1-4020-8914-5.

28. Jaliu, C.; Diaconescu, D.V.; Neagoe, M.; Saulescu, R. Dynamic features of speed increasers from mechatronic wind and hydro systems. Part II. Dynamic aspects. In Proceedings of the Second European Conference on Mechanism Science EUCOMES 08, Casino, Italy, 17-20 September 2008; Springer: Dordrecht, The Netherlands, 2008; pp. 365-373, ISBN 987-1-4020-8914-5.

29. Bevington, C.M.; Bywaters, G.L.; Coleman, C.C.; Costin, D.P.; Danforth, W.L.; Lynch, J.A.; Rolland, R.H. Wind Turbine Having a Direct-Drive Drivetrain. U.S. Patent 7431567B1, 7 October 2008.

30. Marjanovic, N.; Isailovic, B.; Marjanovic, V.; Milojevic, Z.; Blagojevic, M.; Bojic, M. A practical approach to the optimization of gear trains with spur gears. Mech. Mach. Theory 2012, 53, 1-16. [CrossRef]

31. Qiu, J.; Liu, B.; Dong, H.; Wang, D. Type Synthesis of Gear-box in Wind Turbine. Procedia Comput. Sci. C 2017, 109, 809-816. [CrossRef]

32. Climescu, O.; Jaliu, C.; Saulescu, R. Comparative Analysis of Horizontal Small Scale Wind Turbines for a Specific Application. In Proceedings of the 14th IFToMM World Congress, Taipei, Taiwan, 25-30 October 2015. [CrossRef]

33. Saulescu, R.; Neagoe, M.; Jaliu, C. Improving the Energy Performance of Wind Turbines Implemented in the Built Environment Using Counter-Rotating Planetary Transmissions; Materials Science and Engineering-IOP Conference Series: Materials Science and Engineering; IOP Publishing Ltd.: Bristol, UK, 2016. [CrossRef]

34. Saulescu, R.; Jaliu, C.; Neagoe, M. Structural and Kinematic Features of a 2 DOF Speed Increaser for Renewable Energy Systems. Appl. Mech. Mater. 2016, 823, 367-372. [CrossRef]

35. Saulescu, R.; Neagoe, M.; Jaliu, C.; Munteanu, O. Comparative analysis of two wind turbines with planetary speed increaser in steady-state. Appl. Mech. Mater. 2016, 823, 355-360. [CrossRef]

36. Saulescu, R.; Jaliu, C.; Munteanu, O.; Climescu, O. Planetary Gear for Counter-rotating Wind Turbines. Appl. Mech. Mater. 2014, 658, 135-140. [CrossRef]

37. Saulescu, R.; Jaliu, C.; Climescu, O.; Diaconescu, D. On the use of 2 DOF planetary gears as "speed increaser" in small hydros and wind turbines. In Proceedings of the ASME International Design Engineering Technical Conferences \& Computers and Information in Engineering Conference IDETC/CIE 2011, Washington, DC, USA, 25-31 August 2011.

38. Herzog, R.; Schaffarczyk, A.P.; Wacinski, A.; Zürcher, O. Performance and stability of a counter-rotating windmill using a planetary gearing: Measurements and Simulation. In Proceedings of the European Wind Energy Conference \& Exhibition, Warsaw, Poland, 20-23 April 2010.

39. Neagoe, M.; Saulescu, R.; Jaliu, C. Design and Simulation of a 1 DOF Planetary Speed Increaser for Counter-Rotating Wind Turbines with Counter-Rotating Electric Generators. Energies 2019, $12,1754$. [CrossRef]

40. Saulescu, R.; Neagoe, M.; Jaliu, C. Conceptual Synthesis of Speed Increasers for Wind Turbine Conversion Systems. Energies 2018, 11, 2257. [CrossRef]

41. Sapre, R.; Murkute, H.; Agrawal, R. Comparison between single axis wind turbine and counter wind turbine-A case study. Glob. J. Eng. Appl. Sci. 2012, 2, 144-146.

42. Lee, S.; Kim, H.; Lee, S. Analysis of aerodynamic characteristics on a counter-rotating wind turbine. Curr. Appl. Phys. 2010, 10, S339-S342. [CrossRef]

43. Lee, S.; Kim, H.; Son, E.; Lee, S. Effects of design parameters on aerodynamic performance of a counter-rotating wind turbine. Renew. Energy 2012, 42, 140-144. [CrossRef]

44. Farahani, E.M.; Hosseinzadeh, N.; Ektesabi, M. Comparison of fault-ride-through capability of dual and single-rotor wind turbines. Renew. Energy 2012, 48, 473-481. [CrossRef] 
45. No, T.S.; Kim, J.E.; Moon, J.H.; Kim, S.J. Modelling, control, and simulation of dual rotor wind turbine generator system. Renew. Energy 2009, 34, 2124-2132. [CrossRef]

46. Kubo, K.; Hano, Y.; Mitarai, H.; Hirano, K.; Kanemoto, T.; Galal, A.M. Intelligent wind turbine unit with tandem rotors (discussion of prototype performances in field tests). Curr. Appl. Phys. 2010, 10, S326-S331. [CrossRef]

47. Chantharasenawong, C.; Suwantragul, B.; Ruangwiset, A. Axial Momentum Theory for Turbines with Co-axial Counter Rotating Rotors. In Proceedings of the Commemorative International Conference of the Occasion of the 4th Cycle Anniversary of KMUTT Sustainable Development to Save the Earth: Technologies and Strategies Vision 2050: (SDSE2008), Bangkok, Thailand, 11-13 December 2008.

48. Zhamalov, A.Z.; Obozov, A.D.; Kunelbaev, M.M.; Baikadamova, L.S. Capacity and Power Characteristics of Disk Generator with Counter-Rotation of Double-Rotor Wind Turbine. Middle-East J. Sci. Res. 2013, 15, 1655-1662. [CrossRef]

49. Kanemoto, T.; Galal, A.M. Development of intelligent wind turbine generator with tandem wind rotors and double rotational armatures. JSME Int. J. Ser. B 2006, 49, 450-457. [CrossRef]

50. Caiozza, J. Wind Driven Electric Generator Apparatus. U.S. Patent 7227276 B2, 5 June 2007.

51. Miloiu, G.; Dudita, F.1; Diaconescu, D. Modern Mechanical Transmissions; Tehnica: Bucharest, Romania, 1980. (In Romanian)

52. Santoso, S.; Le, H.T. Fundamental time-domain wind turbine models for wind power studies. Renew. Energy 2007, 32, 2436-2452. [CrossRef]

53. Hall, J.F.; Chen, D. Dynamic Optimization of Drivetrain Gear Ratio to Maximize Wind Turbine Power Generation-Part 1: System Model and Control Framework. J. Dyn. Syst. Meas Control 2012, 135, 011016. [CrossRef]

54. Neagoe, M.; Saulescu, R.; Jaliu, C.; Munteanu, O. Reconfigurable Adjustable Planetary Speed Increaser for Wind Turbines and Adjustment Method. Romanian Patent Application No. A/00224, 24 March 2020.

55. Simionescu, P.A.; Smith, M.R. Single-valued function representations in linkage mechanisms design. Mech. Mach. Theory 2000, 35, 1709-1726. [CrossRef]

56. Simionescu, P.A. Contributions to the Optimum Synthesis of Linkage-Mechanisms with Applications. Ph.D. Thesis, Politehnica University of Bucharest, Bucharest, Romania, 1999. Available online: http: //faculty.tamucc.edu/psimionescu/papers.html (accessed on 19 August 2020).

57. Chen, T.H.; Tang, H.C. Meshing Efficiency Analysis of Straight Spur Gear Pair. Appl. Mech. Mater. 2015, 764-765, 314-318. [CrossRef]

(C) 2020 by the authors. Licensee MDPI, Basel, Switzerland. This article is an open access article distributed under the terms and conditions of the Creative Commons Attribution (CC BY) license (http://creativecommons.org/licenses/by/4.0/). 